\title{
Toekomst van de opleiding tot uroloog
}

\author{
Irene Tjiam $^{1}$ Alida Weidenaar ${ }^{2}$
}

Published online: 16 November 2016

(C) The Author(s) 2016. This article is available at SpringerLink with Open Access.

Samenvatting Centralisatie en de verdeling van ingrepen over urologen zouden mogelijk consequenties kunnen hebben voor de urologische opleiding en daarmee de toekomstig uroloog. In dit artikel wordt de huidige opleiding urologie beschreven en gaan we in op wat de hedendaagse veranderingen in de gezondheidszorg mogelijk voor consequenties hebben voor het vak urologie. Tevens worden de resultaten gepresenteerd van een enquête die is afgenomen onder de huidige aios urologie, waarin hun mening wordt gevraagd over welke vaardigheden/ingrepen getraind zouden moeten worden tijdens de opleiding en welke ingrepen de aios zelfstandig zou moeten kunnen uitvoeren aan het einde van de opleiding. Ten slotte zullen we een reflectie geven op de toekomst van de opleiding urologie.

Trefwoorden skills $\cdot$ training $\cdot$ opleiding $\cdot$ certificering

\section{Future perspectives of the urological curriculum}

\begin{abstract}
Centralization and distribution of interventions among urologists may have consequences for the urological residency program and for the next generation urologist. In this article the current urological residency program is described. Also we focus on the consequences the ongoing changes in healthcare may have for the urological profession. In 2015 a survey was administered to current urological residents. The results showed their opinion which
\end{abstract}

\footnotetext{
dr. Irene Tjiam

irenetjiam@hotmail.com

1 Canisius Wilhemina Ziekenhuis, Nijmegen, Nederland

2 Universitair Medisch Centrum Groningen, Groningen, Nederland
}

procedures are considered to be exposed in the residency training program and what procedures a urological resident should be able to perform independently at the end of their residency program. Finally, we will discuss the future perspectives of the urological curriculum.

Keywords skills $\cdot$ training $\cdot$ education $\cdot$ certification

\section{Introductie}

De afgelopen jaren hebben centralisatie en decentralisatie het zorglandschap in beweging gezet. Hiermee wordt bedoeld dat laagvolume-hoogcomplexe zorg zich in toenemende mate is gaan concentreren in zogenaamde centers of excellence en dat hoogvolume-laagcomplexe zorg steeds meer door deze klinieken wordt afgestoten. De verwachting is dat steeds meer specialisten zich gaan toespitsen op een bepaalde subspecialisatie, zodat zij expert worden op dat gebied. Met andere woorden, de invulling van het medisch specialistische vak is an het veranderen. De nieuwe verdeling van medische zorg onder verschillende ziekenhuizen kan grote consequenties hebben voor de medischspecialistische opleiding, vanwege het feit dat niet langer ieder opleidingsziekenhuis kan voldoen aan de gestelde eisen van het kaderbesluit voor het betreffende specialisme.

Daarbij komt nog dat er momenteel een verandering binnen het opleidingsveld gaande is. Onder de titel 'specialistenopleiding op maat' is de afgelopen jaren hard gewerkt aan het opleidingsakkoord uit 2013. Met dit akkoord is met het Ministerie van Volksgezondheid, Welzijn en Sport (VWS) afgesproken dat de gemiddelde opleidingsduur voor alle aios in Nederland wordt verkort. Deze verkorting dient in 2022 gerealiseerd te zijn. Het aantal maanden verkorting is afhankelijk van de totale opleidingsduur, welke per spe- 
cialisme verschilt. Voor de urologie betekent dit concreet dat de opleiding met zeven maanden ingekort moet zijn in 2022 [1].

Deze veranderingen vragen om een aanpassing van de huidige opleidingsstructuur, want uiteraard mogen de eisen die overheid en maatschappij stellen, niet ten koste gaan van de kwaliteit en de inhoud van de opleiding. In een snijdend vak als de urologie luidt een van de belangrijkste vragen: "Straks ben ik wel bevoegd, maar ben ik ook bekwaam?" Daaruit vloeit ook de volgende vraag voort: "Moet je alles nog wel kunnen aan het einde van de opleiding?" In de (nabije) toekomst zullen urologen steeds meer verschillende takenpakketten hebben; de een zal veel of grote chirurgie bedrijven, de ander voert meer kleine chirurgische ingrepen uit en weer anderen zullen zich slechts beperken tot poliklinische chirurgische handelingen. In dit artikel zullen we beschrijven hoe de huidige opleiding eruitziet, wat de visie is van de huidige aios op de opleiding urologie, wat aios achten dat je zou moeten kunnen aan ingrepen als jonge klare en een reflectie op de toekomst van de opleiding urologie.

\section{Huidig urologisch curriculum en theoretische kennis}

Momenteel beslaat de opleiding urologie nog zes jaar. De eerste twee jaar valt onder de common trunk, oftewel de vooropleiding heelkunde. Omdat de opleidingsduur moet worden bekort, is aan aios gevraagd waar de opleiding verkort zou kunnen worden. Hieruit kwam naar voren dat er gekort zou kunnen worden op de duur van de vooropleiding. Aios die in 2016 aan de vooropleiding zijn begonnen, mogen in totaal anderhalf jaar vooropleiding genieten in overleg met de opleider, om vervolgens het urologiegedeelte in vier jaar af te ronden.

Aan het einde van de opleiding urologie wordt er een bepaald kennisniveau verwacht van de beginnend specialist. De theoretische scholing van aios in het urologische deel van hun opleiding bestaat uit tweemaal per jaar een landelijke cursusdag, met de daaraan verbonden toetsing. Sinds 2015 is het landelijke theoretische examen verplicht gesteld voor alle derde- tot en met zesdejaars aios urologie. Wanneer de toets niet gehaald wordt, zal er een schriftelijk herexamen volgen. Mocht ook dit niet succesvol afgesloten worden, dan krijgt de aios een mondeling examen aangeboden. Op deze manier wordt de theoretische kennis gewaarborgd.

\section{Van patiënt naar skills lab: urologisch vaardigheidsonderwijs}

Tot voor kort vond de opleiding van urologen plaats volgens het meester-gezelprincipe, waarbij de patiënt vaak het eerste oefenmedium was. Sinds 2005 is Training in Urology bezig met onderzoek naar alternatieve leermethoden voor vaardigheidstraining, die gebruikt en geïmplementeerd kunnen worden in de opleiding tot uroloog. Deze inspanning heeft onder andere geresulteerd in het Urologisch Vaardigheids Onderwijs (UVO). Het UVO is een verplicht onderdeel van de opleiding urologie en bestaat uit een aantal modules, waarbij voor iedere module een simulatiemodel beschikbaar wordt gesteld. Vervolgens rouleren de verschillende simulatiemodellen tussen de ziekenhuizen van een opleidingsregio. Elk jaar worden alle modules opnieuw doorlopen. Het idee hierachter is onder andere 'de kracht van de herhaling', waarbij aios en opleiders samen verantwoordelijk worden gesteld voor het krijgen respectievelijk geven van onderwijs. Op dit moment worden er acht modules doorlopen, te weten: echo nieren/blaas, laparoscopie (gebaseerd op de BLUS), echo prostaat, acute penispathologie (te weten priapisme en paraphimosis), elektrochirurgie, mid-urethrale slings, transurethrale resectie van de prostaat en flexibele ureterorenoscopie voor urolithiasis. Binnenkort zullen er nieuwe modules geïmplementeerd worden.

\section{Enquête onder aios: "Wat moet je kunnen als je klaar bent?"}

In 2015 werd tijdens een theoretische onderwijsdag een enquête afgenomen onder alle Nederlandse aios urologie uit jaar 3 tot en met jaar 6. Doel van dit onderzoek was het in kaart brengen van de wensen van de Nederlandse aios urologie met betrekking tot de opleiding tot uroloog. De enquête besloeg de thema's demografie, ingrepen, en differentiatie en toetsing, die waren uitgewerkt in tien meerkeuzevragen en zes open vragen:

1. Hoe zou het urologiegedeelte van de opleiding er idealiter uit moeten zien?

2. Welke ingrepen zou je tijdens de opleiding gezien en deels gedaan moeten hebben?

3. Welke ingrepen zou je zelfstandig moeten kunnen aan het einde van de opleiding?

4. Vind je dat er een differentiatie binnen de basisopleiding thuishoort en zo ja, hoe lang vind je dat die basisopleiding moet duren?

5. Vind je dat er, naast een theoretisch examen, ook een praktisch examen zou moeten zijn?

6. Hoe zou je het vinden om in de toekomst als 'office urologist' te werken? 
Verder kregen de aios een lijst voorgelegd van 77 ingrepen en zeven diagnostische methoden. De vraag was of ze vonden dat deze tijdens de opleiding (deels) verricht moeten zijn onder supervisie (exposure) en welke van deze ingrepen de aios aan het einde van de opleiding zelfstandig zou moeten kunnen uitvoeren.

De enquête had een respons van $75,5 \%(n=74)$. Alle aios waren van mening dat er tijdens de opleiding exposure zou moeten zijn aan alle urologische diagnostiek $(100 \%)$. Hieronder vallen echo nieren/blaas/prostaat inclusief afname van prostaatbiopten, cystoscopie, interpretatie van een urodynamisch onderzoek en verrichten van retro-

Tabel 1 Percentage aios dat vindt dat er in de opleiding urologie exposure zou moeten zijn geweest aan bepaalde ingrepen, onderverdeeld in open chirurgie, endo-urologie, laparoscopie, robotgeassisteerde laparoscopie en transplantatie-urologie.

\begin{tabular}{|c|c|}
\hline open chirurgie & $\%$ \\
\hline acute scrotale chirurgie & 100 \\
\hline blaastrauma & 81,8 \\
\hline circumcisie & 100 \\
\hline cystectomie & 90,0 \\
\hline epididymectomie & 91,5 \\
\hline hydro-/spermatocelecorrectie & 100 \\
\hline laparotomie & 98,3 \\
\hline nefrectomie & 100 \\
\hline orchidectomie & 100 \\
\hline orchidopexie & 100 \\
\hline partiële nefrectomie & 85,7 \\
\hline pelviene lymfeklierdissectie & 84,7 \\
\hline plaatsen suprapubische katheter & 96,5 \\
\hline prostatectomie (open) & 86,4 \\
\hline prostatectomie (radicaal) & 84,3 \\
\hline pyelumplastiek & 86,8 \\
\hline sling & 95,4 \\
\hline testisbiopt & 100 \\
\hline ureterre-implantatie & 95,3 \\
\hline urethraplastiek & 82,1 \\
\hline vasectomie & 100 \\
\hline vaso-vasostomie & 85,7 \\
\hline endo-urologische ingrepen & $\%$ \\
\hline botox & 96,8 \\
\hline cystolithotripsie & 100 \\
\hline percutane nefrolitholapaxie & 100 \\
\hline TURP & 100 \\
\hline TURT & 100 \\
\hline ureterstent $(\mathrm{JJ})$ & 95,1 \\
\hline urethraklepresectie & 93,8 \\
\hline uretherotomie & 100 \\
\hline ureterorenoscopie steen & 100 \\
\hline ureterorenoscopie tumor & 100 \\
\hline laparoscopische ingrepen & $\%$ \\
\hline cystectomie & 54,9 \\
\hline
\end{tabular}

Tabel 1 Percentage aios dat vindt dat er in de opleiding urologie exposure zou moeten zijn geweest aan bepaalde ingrepen, onderverdeeld in open chirurgie, endo-urologie, laparoscopie, robotgeassisteerde laparoscopie en transplantatie-urologie. (Vervolg)

\begin{tabular}{ll}
\hline open chirurgie & $\%$ \\
\hline diverticulectomie & 51,4 \\
lymfeklierdissectie & 76,5 \\
nefrectomie & 87,0 \\
part nefrectomie & 74,0 \\
prostatectomie (radicaal) & 75,5 \\
pyelumplastiek & 81,1 \\
testis/varicocele & 70,6 \\
robotgeassisteerde ingrepen & $\%$ \\
cystectomie & 34,3 \\
diverticulectomie & 31,3 \\
lymfeklierdissectie & 53,0 \\
nefrectomie & 44,8 \\
partiële nefrectomie & 41,2 \\
prostatectomie (radicaal) & 60,3 \\
pyelumplastiek & 35,3 \\
testis/varicocele & 30,3 \\
transplantatie-urologie & $\%$ \\
donor nefrectomie & 22,9 \\
niertransplantatie & 25,7 \\
revisie niertransplantatie & 24,3 \\
\hline
\end{tabular}

grade pyelografie. Wanneer we kijken naar de ingrepen die met open chirurgie plaatsvinden, vond meer dan $80 \%$ van de aios dat er in ieder geval exposure moest zijn geweest aan 22 urologische open ingrepen (tab. 1).

Meer dan $90 \%$ van de aios vond dat alle endo-urologische ingrepen (deels) uitgevoerd zouden moeten zijn onder supervisie. Wat betreft de laparoscopische ingrepen, was het merendeel van mening dat tijdens de opleiding exposure moet zijn geweest aan nefrectomie $(87 \%)$, pyelumplastiek $(81 \%)$, lymfeklierdissectie $(77 \%)$, radicale prostatectomie $(75 \%)$, partiële nefrectomie ( $74 \%)$, cystectomie $(54 \%)$ en diverticulectomie (51\%). Naar de mening van $60 \%$ van de aios zou er exposure moeten zijn geweest aan robotgeassisteerde radicale prostatectomie.

Volgens een meerderheid van de aios zou een jonge klare in ieder geval alle diagnostiek zelfstandig moeten kunnen uitvoeren en interpreteren, inclusief steenbehandeling middels extracorporal shockwave lithotripsy (ESWL). Fig. 1 toont van welke open ingrepen wordt verwacht dat die zelfstandig uitgevoerd kunnen worden aan het einde van de opleiding. Opvallend is dat met name de scrotale chirurgie als minimale vereiste werd beschouwd door nagenoeg alle aios. In fig. 2 staan de endo-urologische ingrepen die zelfstandig uitgevoerd zouden moeten kunnen worden aan het einde van de opleiding tot uroloog. Wat betreft de laparoscopische nefrectomie, vond slechts $24,3 \%$ van de aios 


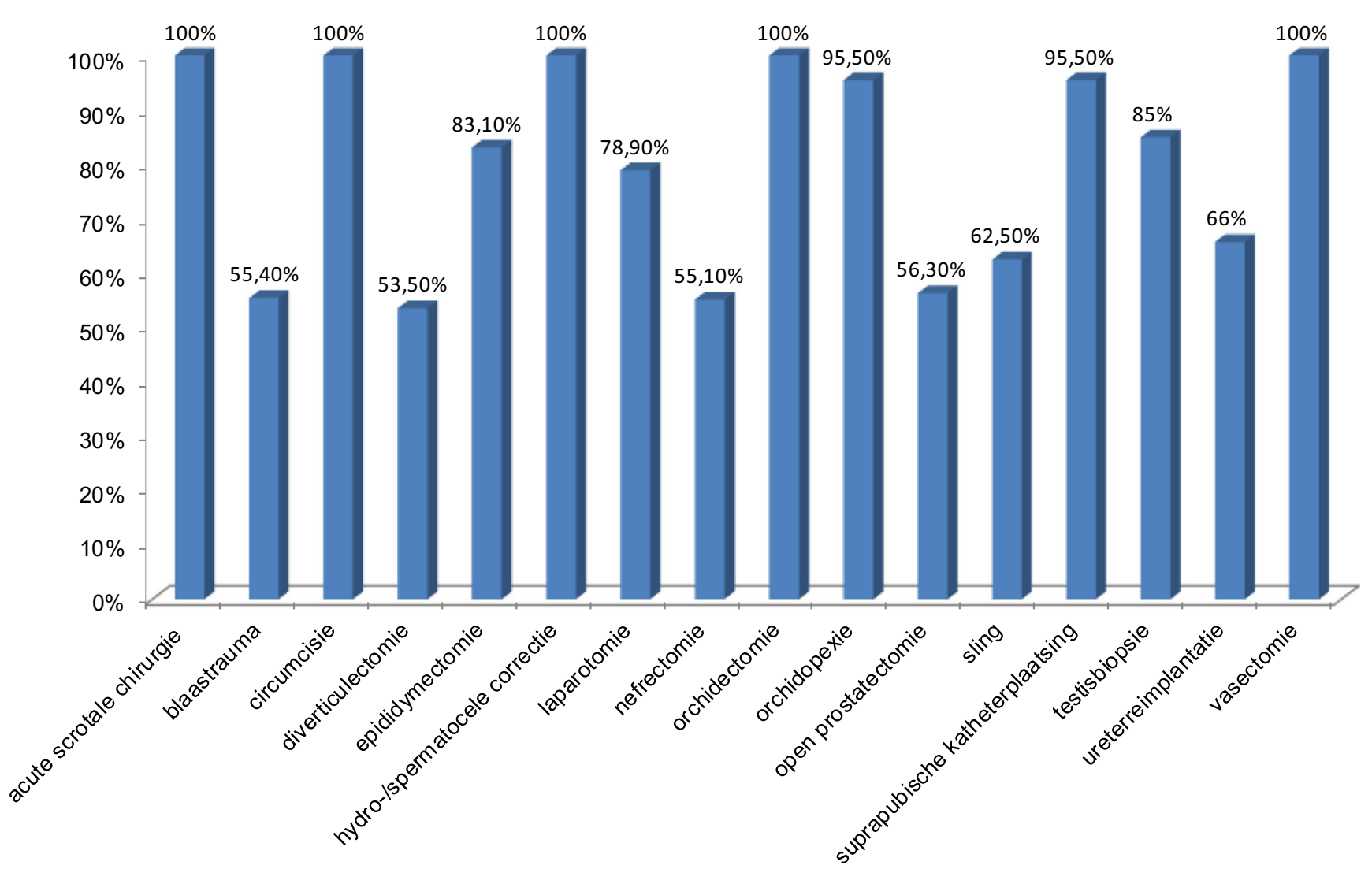

Figuur 1 Percentage aios dat vindt dat bepaalde open urologische ingrepen zelfstandig uitgevoerd moet kunnen worden door de aios aan het einde van de opleiding urologie. (RPLND retroperitoneale lymfeklierdissectie).

dat je deze zelfstandig zou moeten kunnen uitvoeren aan het einde van het zesde jaar. Van de overige laparoscopische ingrepen was minder dan $20 \%$ van mening dat je deze zelfstandig zou moeten kunnen doen (fig. 3). Tussen de 0 en $4,3 \%$ van de aios nam het standpunt in dat je een robotgeassisteerde operatie zelfstandig zou moeten kunnen uitvoeren als jonge klare. $7,1 \%$ van de aios vond dat je zelfstandig een robotgeassisteerde lymfeklierdissectie zou moeten kunnen doen. Nagenoeg geen enkele aios vond dat transplantatie-urologie tot het eisenpakket behoort dat je zelfstandig zou moeten kunnen als jonge uroloog $(2,9 \%)$.

Een baan als 'office uroloog' werd door 15 van de 74 aios $(20,3 \%)$ overwogen. Een office uroloog werd in de enquête omschreven als een uroloog die zijn opleiding heeft afgerond en die in ieder geval de poli en bepaalde basisingrepen beheerst. Welke ingrepen er onder basisingrepen werden verstaan, was niet nader beschreven. Voor de andere ingrepen zou verdere subspecialisatie binnen een differentiatie, dan wel een fellowship, zijn vereist.

\section{Toetsing en certificering tijdens de opleiding}

In 2007 publiceerde de Inspectie voor de Gezondheidszorg (IGZ) het rapport 'Risico's minimaal invasieve chirurgie onderschat' [2]. De Inspectie stelde hierin onder andere dat het ontbrak aan richtlijnen voor het beoefenen van minimaal invasieve chirurgie, alsook aan richtlijnen voor de opleiding in minimaal invasieve chirurgie. Sindsdien is er een groeiend besef onder opleiders urologie in Nederland dat in ieder geval de kennis van en vaardigheden in de minimaal invasieve chirurgie moeten worden gestandaardiseerd. Dit resulteerde in het Basic Laparoscopic Urological Skills (BLUS) examen, dat in 2009 werd geïmplementeerd als verplichte toets voor aios urologie aan het eind van de vooropleiding [3]. Het BLUS-examen bestaat uit een theoretische toets en een praktisch examen voor basisvaardigheden laparoscopie. Wanneer een van beide onderdelen niet wordt gehaald, volgt er een herexamen.

$\mathrm{Nu}$ rijst de vraag of alle andere vaardigheden ook gecertificeerd moeten worden binnen de opleiding. Uit de enquête bleek dat $71 \%$ van de aios geen praktisch examen buiten de eigen kliniek wenst. Van de aios die wel een examen buiten de eigen kliniek zien zitten, gaven vijf de suggestie om het examen jaarlijks af te leggen. Anderen 
Figuur 2 Percentage aios dat vindt dat bepaalde endo-urologische ingrepen zelfstandig uitgevoerd moet kunnen worden aan het einde van de opleiding urologie. $P N L$ percutane nefrolitholapaxie; TURP/TURT transurethrale resectie van prostaat/ tumor; URS ureterorenoscopie.

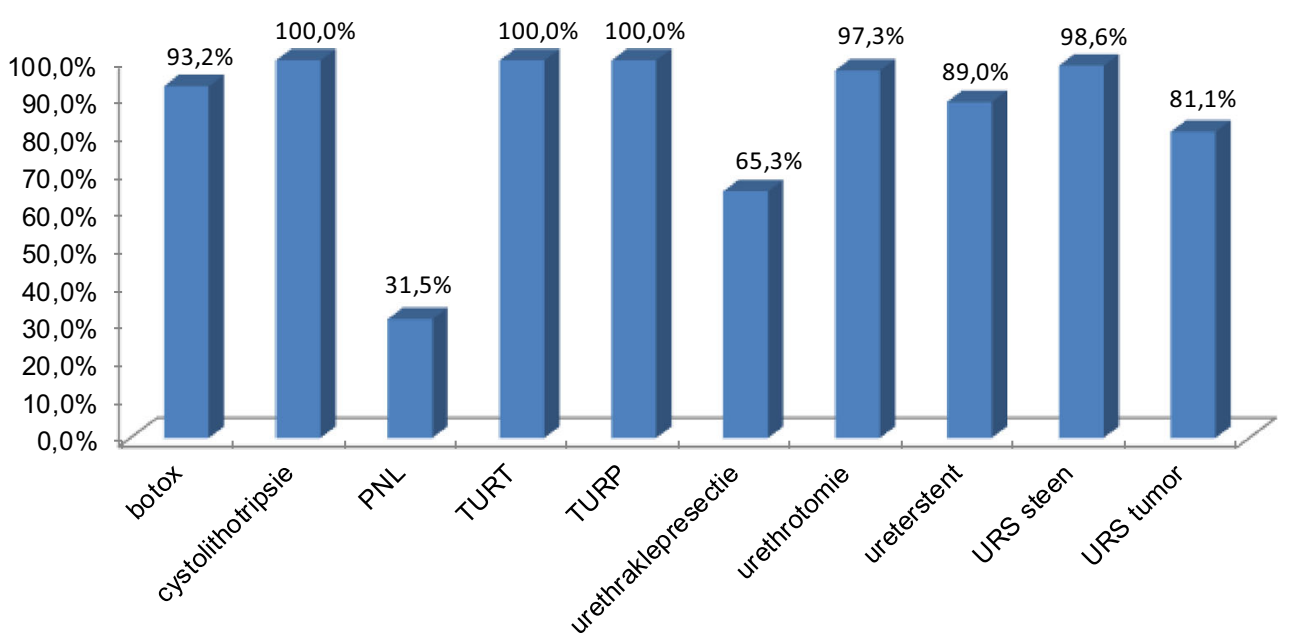

Figuur 3 Percentage aios dat vindt dat bepaalde laparoscopische ingrepen zelfstandig uitgevoerd moet kunnen worden door de aios aan het einde van de opleiding urologie.

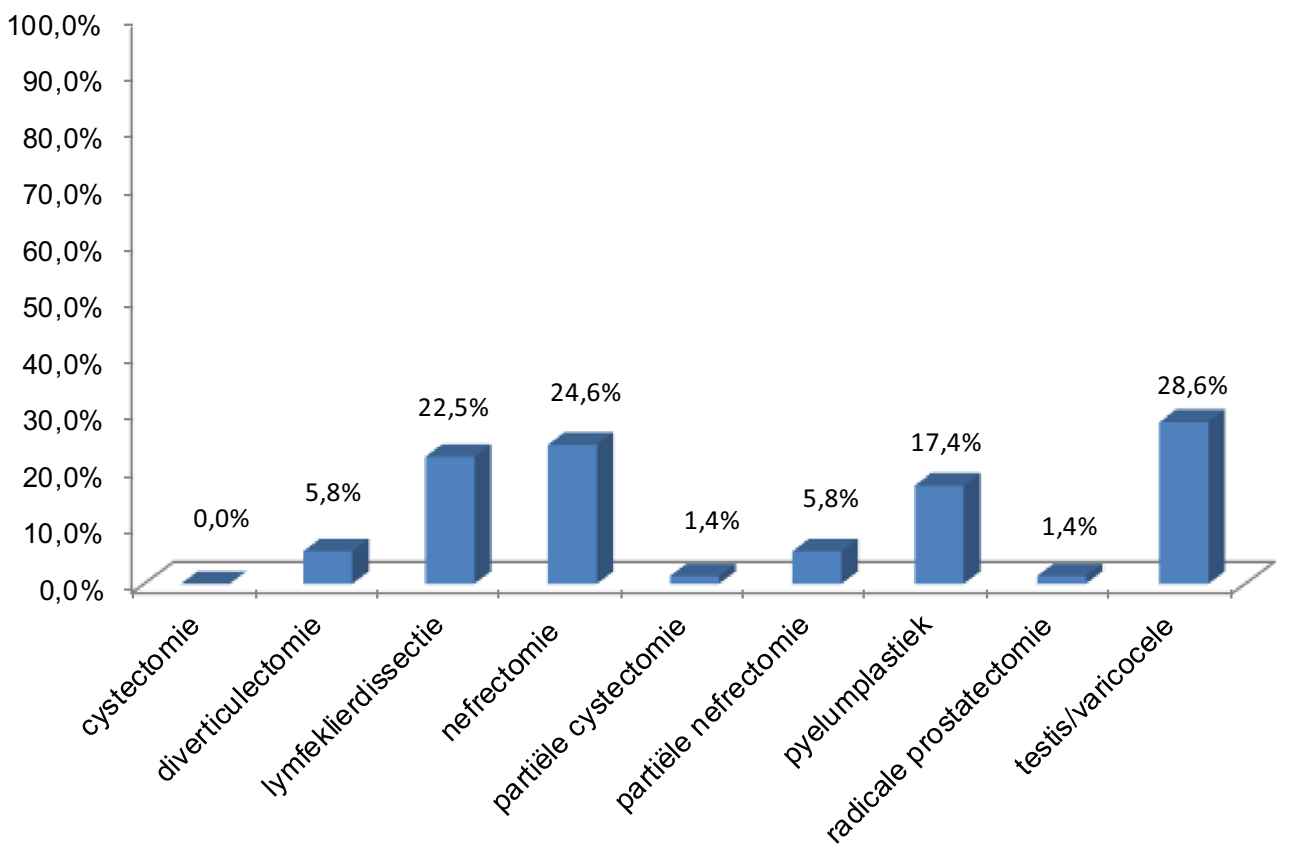

gaven aan een praktisch examen te willen aan het einde van de opleiding. Vier aios gaven de suggestie om de opleider een praktisch examen basale vaardigheden of ingrepen te laten afnemen bij derde- en vierdejaar aios urologie.

Op dit moment houdt elke aios een digitaal portfolio bij, waarin de ingrepen worden geregistreerd die hij (deels) onder supervisie of zelfstandig heeft uitgevoerd. Als het goed is, wordt een aantal van deze ingrepen ook beoordeeld door de supervisor middels een Objective Structured Assessment of Technical Skills (OSATS) [4]. Wellicht dat de OSATS in de toekomst een grotere rol kan spelen in het kader van certificering van vaardigheden.

\section{De ideale opleiding}

Uit de enquête blijkt dat een meerderheid van de aios behoefte heeft aan differentiatie binnen de opleiding. In de ideale opleiding vindt het vijfde jaar van de opleiding in een perifeer ziekenhuis plaats $(80 \%)$. Het beste moment voor differentiatie zou in het zesde jaar zijn $(73 \%)$, gedurende een periode van 6 tot 12 maanden $(42,5-52,1 \%)$. Suggesties vanuit de aios zijn onder andere om in het laatste jaar van de opleiding een differentiatietraject van een half jaar academisch en een half jaar algemeen te volgen, al dan niet buiten de Onderwijs- en Opleidingsregio (OOR). Er werd zelfs geopperd om een differentiatieperiode te creëren, opgevolgd door een fellowship. 


\section{Toekomstvisie van de aios op de opleiding Urologie}

Wanneer we ons licht laten schijnen over de toekomst van de opleiding tot uroloog, speelt er een aantal zaken een rol.

Ten eerste het theoretisch onderwijs. Zoals hier beschreven, bestaat het theoretisch onderwijs in het huidige curriculum uit twee landelijke onderwijsdagen en een examen. Nieuw is dat de toets sinds 2015 verplicht gehaald moet worden. Aangezien hier consequenties aan verbonden zullen worden, vindt er een professionaliseringsslag plaats door de toetsvragen te laten beoordelen door onderwijskundigen. Voor de komende jaren verwachten we dat het landelijke onderwijs blijft bestaan, ook in het nieuwe curriculum. Want hoewel niet iedere uroloog bijvoorbeeld zelfstandig een robotgeassisteerde radicale prostatectomie uit hoeft te kunnen voeren, is het wel wenselijk dat bepaalde basiskennis over deze ingreep en indicatiestelling aanwezig is. Omdat in een cyclus van vier jaar alle onderwerpen aan bod komen, zullen nagenoeg alle aios aan het eind van hun vierde jaar de thema's allemaal behandeld hebben. Uiteraard is het de verantwoordelijkheid van de aios om, naast de verplichte onderwijsdagen, extra kennis te vergaren, bijvoorbeeld in het kader van een differentiatie. Om die reden zullen in de toekomst additionele (landelijke) cursussen met minimaal een voldoende afgerond moeten worden.

Ten tweede het vaardigheidsonderwijs. Tijdens de vooropleiding dienen de snijdende basisvaardigheden verkregen te worden. Deze periode is ingekort van twee naar anderhalf jaar. Dit zal naar verwachting weinig problemen opleveren, mits er gekort wordt op de mammapoli's en ook de gipskamers minder frequent bezocht hoeven te worden. Als de aios dan eenmaal is aangekomen bij het vak waarvoor is gekozen, zal ook hierin training plaats moeten vinden teneinde de verrichtingen onder de knie te krijgen.

Uit de enquête onder de aios blijkt dat urologische diagnostiek, basisendo-urologie en scrotale ingrepen tot het minimale eisenpakket van zelfstandig uit te voren ingrepen behoren. Belangrijk is dat er voldoende blootstelling aan deze ingrepen is tijdens de opleiding en dat hiermee, ondanks de centralisatie van de zorg, rekening gehouden wordt. Eenmaal uroloog, zullen deze verrichtingen immers ook verricht moeten worden tijdens de diensten. De UVO-modules kunnen hier een belangrijke rol in spelen.

Het UVO heeft een aantal landelijke cursusdagen vervangen, zoals de voormalige echo- en endocursus. De aios is hiervoor nu afhankelijk van de lokale opleider. Waar dus eerst een expert een voordracht gaf en zijn of haar ervaring deelde over een bepaalde aanpak, lijkt de aios vanaf heden afhankelijk te zijn van één methode, namelijk die van zijn eigen opleidingskliniek. Al het onderwijs wordt echter ondergebracht in modules. Deze modules worden samengesteld door expert-urologen uit verschillende klinieken. Om de kwaliteit te waarborgen, wordt de module, voorafgaand aan de implementatie in de opleiding, nog gekeurd en geaccordeerd door de commissie UVO (CUVO), bestaande uit weer andere urologen. Bovendien omvat het UVO onderwerpen en ingrepen die in alle klinieken worden uitgevoerd. De verwachting is dan ook dat het aantal modules de komende jaren uitgebreid zal worden en, wat ons betreft, toegespitst zal worden op het minimale eisenpakket van de opleiding. Gezien de logistiek rondom de endo-urologische modules kan er wellicht in de toekomst een (jonge klare) uroloog met een UVO-bus door Nederland rijden om alle modules te begeleiden.

Duidelijk is dat we niet allemaal meer als 'breed inzetbare' uroloog opgeleid kunnen worden. Uit de enquête blijkt dat ook de aios behoefte heeft aan differentiatie. We zullen toegaan naar een competentiegerichte opleiding, waarbij niet de duur van de opleiding bepalend is, maar het takenpakket waarin men zich bekwaam heeft getoond. Dit zal in het nieuwe curriculum uitgevoerd worden door middel van Entrustable Professional Activities (EPA's). De vraag die de aios zichzelf moet stellen is: 'Wat voor uroloog wil ik worden?' Aan de hand van de keuze van de EPA's zullen ook een bepaald uitstroomprofiel en differentiatie kunnen volgen. Het aanleren van specifieke vaardigheden wordt bepaald door de gekozen EPA's. De hoop en verwachting is dat dit proces in het laatste en voorlaatste jaar van de opleiding doorlopen kan worden, want ook hier kan zich een probleem aandienen. Immers, hoewel bepaalde EPA's goed met virtual reality of op kadavers geoefend kunnen worden (denk aan minimaal-invasieve handelingen, zoals laparoscopie of robot), zal uiteindelijk ook in de praktijk geopereerd moeten worden en niet iedere kliniek kan de vereiste vaardigheden bieden. In het kader van de individualisering, zal dan ook per aios bekeken moeten worden hoe het laatste deel van de opleiding precies ingevuld dient te worden, al dan niet binnen de eigen OOR.

Centralisatie kan erin resulteren dat niet iedere kliniek het gewenste aantal aios meer zal krijgen. Voor de praktijkvoering in de kliniek kan dat consequenties hebben. Daarbij dient men ook rekening te houden met het profiel van de toekomstige (en misschien al wel huidige) aios, aangezien steeds meer aios op zoek zijn naar de balans tussen werk en privé. Uiteraard zal ook financiering een rol spelen. Hoewel aios graag fellowships verkrijgen, is het maar de vraag of in de toekomst geld voor fellowships beschikbaar is. Om deze reden lijkt het reëler om de differentiaties meer tot uitvoering te laten brengen zoals hierboven beschreven.

Minstens zo belangrijk is de vraag 'wat voor uroloog wil de maatschappij dat je wordt?' Er zijn evidente signalen dat het zorglandschap revolutionaire veranderingen ondergaat; de opleiding zal met de stroom mee moeten bewegen. Een van die veranderingen is, dat de patiënt steeds meer de gang van zaken in de spreekkamer bepaalt. Dit betekent dat we ons niet alleen zullen moeten richten op de theoreti- 
sche kennis en vaardigheden, maar ook op communicatieve vaardigheden, de besluitvorming in overleg met de patiënt en de multidisciplinaire overlegorganen. Wellicht zullen we als discipline ontwikkelingen doormaken in de richting van buitenlandse praktijken, waar urologen werken die de indicaties stellen en urologen die de ingrepen uitvoeren. Ook neventaken als management en financiën zijn een belangrijk onderdeel van het 'specialist zijn'. Door de aios als jongste partij van de maatschap te beschouwen én te behandelen, bijvoorbeeld binnen een profileringsstage, kan ook op deze vlakken kennis en kunde verworven worden. Mogelijk wordt ook hier in de toekomst een EPA aan gewijd.

Open Access This article is distributed under the terms of the Creative Commons Attribution 4.0 International License (http:// creativecommons.org/licenses/by/4.0/), which permits unrestricted use, distribution, and reproduction in any medium, provided you give appropriate credit to the original author(s) and the source, provide a link to the Creative Commons license, and indicate if changes were made.

\section{Literatuur}

1. Opleidingsakkoord. Specialistenopleiding op Maat. www. specialistenopleidingopmaat.nl (2016). Geraadpleegd op: 21 mei 2016.

2. IGZ. Risico's minimaal invasieve chirurgie onderschat, kwaliteitssysteem voor laparoscopische operaties ontbreekt. 2007. www.igz. nl. Geraadpleegd op: 21 mei 2016.

3. Tjiam IM, Schout BMA, Hendrikx AJM, et al. CPM 2013. Program for laparoscopic urological skills assessment: setting certification standards for residents. Minim Invasive Ther Allied Technol. 2013;22(1):26-32.

4. Martin JA, Regehr G, Reznick R, et al. Objective structured assessment of technical skill (OSATS) for surgical residents. Br J Surg. 1997;84(2):273-8.

dr. Irene Tjiam uroloog in opleiding

dr. Alida Weidenaar uroloog in opleiding 